\title{
Hydrosols of Titanium Dioxide Nanoparticles Containing Ti(IV) Peroxo Complexes: Modification, Optical Properties, Morphology, and Bleaching Kinetics
}

\author{
I. V. Yaminsky ${ }^{a, b, c}$, A. I. Akhmetova ${ }^{b, c}$, V. N. Kur'yakov ${ }^{d}$, L. N. Obolenskaya ${ }^{e, ~ *}$, and N. V. Kotlyarova ${ }^{e}$ \\ ${ }^{a}$ Moscow State University, Moscow, 119991 Russia \\ ${ }^{b}$ Belozersky Research Institute of Physicochemical Biology, Moscow State University, Moscow, 119234 Russia \\ ${ }^{c}$ Advanced Technologies Center, Moscow, 119311 Russia \\ ${ }^{d}$ Oil and Gas Research Institute, Russian Academy of Sciences, Moscow, 119333 Russia \\ e State budget funded education institution Public School no. 2065, Moscow, 108811 Russia \\ *e-mail:urraa_2@mail.ru \\ Received February 8, 2020; revised July 6, 2020; accepted July 7, 2020
}

\begin{abstract}
This paper reports the development and characterization of new inexpensive and safe light-timetemperature indicators for products of the pharmaceutical and food industries. For this purpose, we have prepared and characterized stable sols of titanium dioxide nanoparticles modified with titanium(IV) peroxo complexes. Electronic absorption spectroscopy, dynamic light scattering, scanning probe microscopy, and experimental kinetic data demonstrate that, varying synthesis conditions and, hence, the stability of the Ti(IV) peroxo complexes, one can ensure that their bleaching is symbatic with the degradation of a particular labeled object after the expiry date, and/or in the case of the required temperature conditions being not fulfilled, and/or during storage in the light. The most important result of this study is that we have found correlations between modification conditions of titanium peroxide sols, their optical properties, the morphology of films produced from them, and their bleaching kinetics under illumination.
\end{abstract}

Keywords: hydrosols, titanium dioxide, titanium(IV) peroxo complexes, scanning probe microscopy, electronic absorption spectroscopy

DOI: $10.1134 /$ S0020168520110175

\section{INTRODUCTION}

At present, one topical issue is the ability to monitor

(1) how storage conditions of pharmaceutical preparations and food products (especially such as fermented dairy food with probiotics) are fulfilled;

(2) the completeness of thermal (steam or air) sterilization of medical tools, incubation apparatuses, etc.; and

(3) the acidity of various aqueous media (including sera and others).

Titanium peroxide nanofilms developed by us are suitable for repeated use for indication of all three of the above parameters.

As shown in previous work, using a simple one-step synthesis from solvated titanyl sulfate and a hydrogen peroxide solution (in autothermal mode) one can obtain hydrosols of monodisperse titanium peroxo acid nanoparticles, capable of forming stable nanostructured films on a variety of surfaces (fibers of sterile gauze wipes, glass, mica, and others). Such films are promising materials for producing a new class of light-time-temperature indicators, because they contain bright red titanium(IV) peroxo complexes, which slowly bleach (in a temperature-dependent process) when stored in the light. Varying synthesis conditions and, hence, the stability of the Ti(IV) peroxo complexes, one can ensure that their bleaching is symbatic with the degradation of a particular labeled object after the expiry date, and/or in the case of the required temperature conditions being not fulfilled, and/or during storage in the light, and/or during thermal sterilization. Moreover, bleaching occurs at a certain rate (determined by synthesis conditions), which allows for controlled fabrication of nanomaterials for the production of indicator labels of objects with various expiry dates and various requirements for temperature-light storage conditions. As a tool for reducing the stability of peroxo groups, we used either an increase in $\mathrm{pH}$ or their partial oxidation via the addition of silver nitrate. 
We found preliminary correlations between the amount of $\mathrm{Ag}(\mathrm{I})$ cations added to titanium peroxide sol (relative to the amount of Ti(IV)), characteristics of the sol (optical properties (according to electronic absorption spectroscopy data) and micromorphology (according to scanning probe microscopy (SPM) data)), and its bleaching kinetics (in accelerated mode, under the effect of UV irradiation).

The controllability of characteristics of the nanomaterials thus prepared, in combination with their nontoxicity and low prime cost and the energy efficiency of their synthesis, makes it possible to envisage their wide applicability for labeling a vast diversity of products in the pharmaceutical, food, and cosmetic industries. Moreover, the choice of $\mathrm{Ag}^{+}$cations as a modifier, capable of being partially reduced to bacteriostatic nano-Ag, suggests the possibility of subsequently developing a synthesis process, for example, for a liquid peroxo-containing colored antiseptic agent for medical institutions, whose color disappears in parallel with the degradation of its performance characteristics.

The purpose of this work was to develop a process for targeted synthesis of a nanomaterial for lighttime-temperature expiry date indicator bleaching at a predetermined rate.

\section{THEORETICAL ANALYSIS}

The first time-temperature indicators were designed starting in the late 1980s. Nevertheless, there is still no general strategy for producing reliable, inexpensive, and environmentally friendly (in all synthesis steps) materials for appropriate labeling.

Previously, researchers obtained time-temperature indicators based on $\mathrm{Ag} / \mathrm{Au}$ (core/shell) plasmonic nanocomposites [1] or organic polymers on $\mathrm{SiO}_{2}$ [2] capable of indicating that a product or medicine was unsuitable because the temperature conditions of storage were violated and/or the hold time was exceeded. However, their synthesis included rather many steps and, moreover, the resultant materials made it possible to monitor only the duration and temperature conditions of storage of the labeled object, but not its possible photodegradation. Similarly, neither Koutsoumanis et al. [3] nor Han et al. [4] mentioned an indicator capable of revealing destruction of a product/preparation as a consequence of storage in the light.

Owing to their unique optical properties and a combination of chemical inertness (that is, nontoxicity) and high adsorption capacity and photocatalytic activity [5], $\mathrm{TiO}_{2}$ nanoparticles have been a functional basis of a wide range of nanomaterials for several decades now [6]. At the very beginning of research aimed at optimizing conditions of rapid low-temperature synthesis of nano- $\mathrm{TiO}_{2}$ ( $\eta$-phase and anatase) from titanyl sulfate solvates, some correlations were found [7] between synthesis parameters and the characteristics and properties (absorptive and photocatalytic) of the resultant materials. However, for lack of photoabsorption in the visible spectral region, nano$\mathrm{TiO}_{2}$ found no application as sensors [8].

Colored titanium(IV) peroxo complexes are traditionally used in qualitative and quantitative analysis [9]. Their bright color is due to $\mathrm{O}-\mathrm{O}$ bond polarization under the effect of titanium(IV) atoms. On the other hand, the stability and water solubility of the $\mathrm{Ti}(\mathrm{IV})$ peroxo complexes have made the synthesis of titanium dioxide nanoparticles via the so-called peroxo route rather widespread. Note that, as shown for example by Kreshkov [10], varying Ti(IV) peroxo complex preparation and destruction conditions one can obtain a particular nano- $\mathrm{TiO}_{2}$ polymorph in a controlled manner.

As shown in our previous study [11], Ti(IV) oxide peroxide nanoparticles prepared by hydrothermal treatment from titanyl sulfate under specially selected conditions bleach (on account of the decomposition of peroxo complexes) as a result of storage at room temperature (in the dark) for a year. Moreover, it is shown that varying the time when peroxo groups are added to a reaction mixture allows one to drastically change the bleaching rate of the peroxo complexes in the composition of the resulting nanoparticles, to the point of complete termination of the process (which can be exemplified by $\mathrm{TiO}_{x}\left(\mathrm{O}_{2}\right)_{2-x}\left(\mathrm{H}_{2} \mathrm{O}\right)_{m}$ nanoparticles, which retain their original color during both storage in the light for many years and annealing at temperatures of up to $400^{\circ} \mathrm{C}$ ) [12]. In addition, correlations were found between the composition of the Ti(IV) peroxo complexes, the micromorphology of their thin films (as assessed by optical microscopy and scanning electron microscopy), and the temperature range of the formation of various $\mathrm{TiO}_{2}$ polymorphs during annealing [13]. On the other hand, as shown by Savinkina et al. [14] one of the most effective tools for examining nanofilm morphology is SPM. This method was successfully used by Yaminsky et al. with application to $\mathrm{TiO}_{2}$ nanofilms and by a number of groups (see, for example, Kumar et al. [16]) with application to $\mathrm{TiO}_{2} / \mathrm{Ag}$ nanocomposites.

Ubonchonlakate et al. [17] and Muflikhun et al. [18] described the formation of noticeable growth "inhibition zones" for various strains of bacteria around substrates impregnated with $\mathrm{TiO}_{2} / \mathrm{Ag}$ sols (owing to the combination of the photocatalytic properties of $\mathrm{TiO}_{2}$ and the plasmon resonance effect on $\mathrm{Ag}$ ). Tryba et al. [19] described the use of nano- $\mathrm{TiO}_{2} / \mathrm{Ag}$ on 
fabric supports as a disinfectant, and Rodriguez et al. [20] reported the application of $\mathrm{TiO}_{2} / \mathrm{Ag}$ in self-cleaning coatings.

We now turn to the crystal structure of the nanoparticles in question. As shown in previous work, mixing $\mathrm{TiOSO}_{4} \cdot 2 \mathrm{H}_{2} \mathrm{O}$ with a $37-50 \% \mathrm{H}_{2} \mathrm{O}_{2}$ solution leads to the formation of a nano- $\left[\mathrm{TiO}_{x}\left(\mathrm{O}_{2}\right)_{2-x}\left(\mathrm{H}_{2} \mathrm{O}\right)_{m}\right]$ phase, in the case of both stirring of the reaction mixture without external heating (with self-heating due to partial $\mathrm{H}_{2} \mathrm{O}_{2}$ decomposition) and its thermostating at $76 \pm 0.1^{\circ} \mathrm{C}$. Analysis of synchrotron X-ray diffraction patterns of this phase (Kurchatov Institute National Research Center) made it possible to determine the unit-cell parameters of its orthorhombic structure: $a=$ 3.880(5) $\AA, b=11.64(2) \AA$, and $c=12.64(1) \AA$. This phase is an anatase-related superstructure and converts into anatase during prolonged annealing above $400^{\circ} \mathrm{C}[12]$.

\section{EXPERIMENTAL}

Hydrosols of $\mathrm{TiO}_{2}$ modified with titanium(IV) peroxo complexes were prepared by reacting $\mathrm{TiOSO}_{4}$. $2 \mathrm{H}_{2} \mathrm{O}$ (Aldrich, for synthesis) and a $37 \% \mathrm{H}_{2} \mathrm{O}_{2}$ solution (Spektr-Khim, pure grade, Russian Federation State Standard GOST 177-88). In the first step, a weighed amount $(1 \mathrm{~g})$ of titanyl sulfate was dispersed in $60 \mathrm{~mL}$ of the $37 \%$ hydrogen peroxide solution. The mixture was then stirred on a magnetic stirrer $(800 \mathrm{rpm})$ at room temperature. The interaction between the reactants was accompanied by gradual self-heating of the reaction mixture due to heat release as a result of a side reaction: partial hydrogen peroxide decomposition. At a temperature from 35 to $40^{\circ} \mathrm{C}$, the solution became transparent in $30 \mathrm{~min}$. After an additional $20 \mathrm{~min}$, the solution began to boil, following which it was cooled on a water bath.

To gradually raise the $\mathrm{pH}$ of the sols, a $0.1 \mathrm{M}$ $\mathrm{NaOH}$ solution was added dropwise to them. The peroxo groups in the composition of the sols were gradually oxidized by dropwise adding $0.1 \mathrm{M} \mathrm{AgNO}_{3}$.

Electronic absorption spectra were measured on an Ekros PE-400 spectrometer. The background spectrum was obtained using water.

The sols were characterized by correlation spectroscopy (dynamic light scattering spectroscopy) on a Fotokor instrument. Prior to measurements, the sols were filtered though a syringe filter with a pore size of $0.45 \mu \mathrm{m}$. Next, $10 \mu \mathrm{L}$ of the filtrate was diluted tenfold with water.

The surface of the films produced using the hydrosols under consideration was scanned in contact mode on a FemtoSkan scanning probe microscope (Nanotechnologies Youth Innovative Creativity Centre,
Faculty of Physics, Moscow State University) with the use of a CSG10 silicon cantilever (Lukin Research Institute of Physical Problems).

To study sol bleaching kinetics, a $100-\mathrm{mL}$ sample was exposed to UV radiation (OUFK-02 quartz lamp, $125 \mathrm{~W}$ power) at a constant temperature of $22-25^{\circ} \mathrm{C}$. Every $30 \mathrm{~min}$, we took a $5-\mathrm{mL}$ aliquot and measured its electronic absorption spectrum on an Ekros PE400 spectrophotometer. In accordance with the Bouguer-Lambert-Beer law, the peak absorbance of the $400-\mathrm{nm}$ band was thought to be proportional to the residual concentration of the Ti(IV) peroxo complexes. To evaluate the rate constant (under the assumption that photodestruction was a pseudo-firstorder reaction), the kinetic data were represented as semilog plots and the rate constant was evaluated from the slope of the corresponding straight line (with no allowance for the induction period of deceleration (during the first $30 \mathrm{~min}$ of irradiation)). In all cases, linear fitting validity was at least 0.98 .

\section{RESULTS AND DISCUSSION}

Dynamic light scattering. According to dynamic light scattering spectroscopy data, the particle size in the silver-free sol is 80 to $100 \mathrm{~nm}$. Raising the $\mathrm{pH}$ of this sol by about 0.1 or adding silver nitrate (to a silver : titanium molar ratio of $1: 10$ ) increases the particle size to $100-110 \mathrm{~nm}$. Note that all of the sols turned out to be monodisperse. However, specific features of the method under consideration make it impossible to find better correlations between the amount of modifiers added and the particle size.

Electronic absorption spectroscopy. It is seen from the spectra in Fig. 1 (where the number of each spectrum specifies the volume $(\mathrm{mL})$ of the alkali solution added) and the inset therein that, with increasing sol $\mathrm{pH}$, the intensity of the absorption band due to the titanium(IV) peroxo complexes (proportional to the concentration of these complexes) decreases monotonically. This is accompanied by a systematic hypsochromic shift of the peak position of the absorption band due to the titanium(IV) peroxo complexes from 400 to $360-370 \mathrm{~nm}$. Note that it is because of this shift of the absorption band of the Ti(IV) peroxo complexes and, accordingly, its being obscured by the intrinsic absorption edge of $\mathrm{TiO}_{2}$ (a semiconductor with a band gap of $3-3.2 \mathrm{eV}$ ) that the plot of the absorbance against the volume of the $\mathrm{NaOH}$ solution added (Fig. 1, inset) has no data points corresponding to the last two absorption spectra. Note also that the light scattering intensity in the "white" spectral region increases very little, if at all, suggesting that the sol retains aggregative stability. 


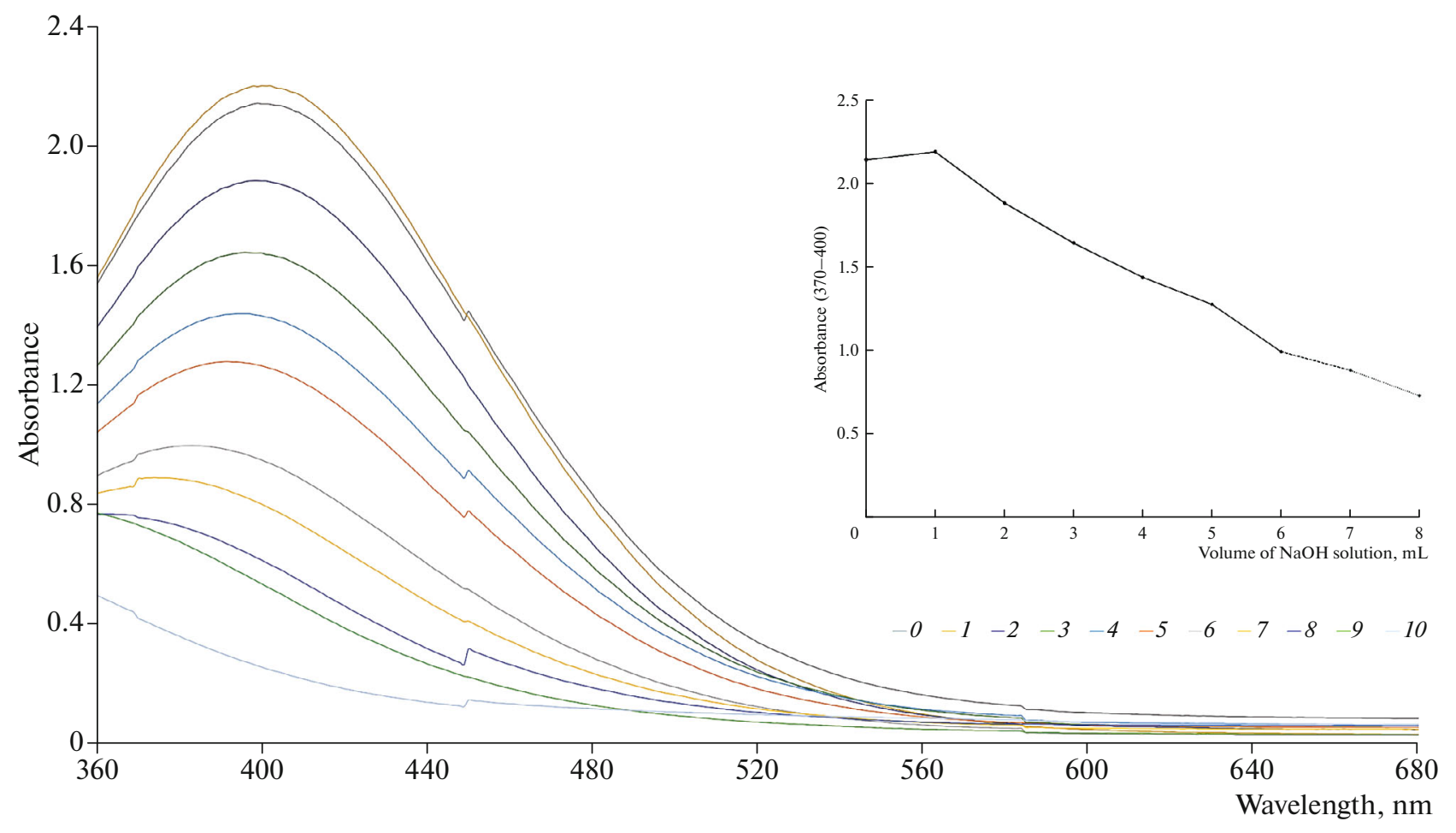

Fig. 1. Electronic absorption spectra of the $\mathrm{TiO}_{2}$ sols containing $\mathrm{Ti}(\mathrm{IV})$ peroxo complexes and modified by adding a $\mathrm{NaOH}$ solution.

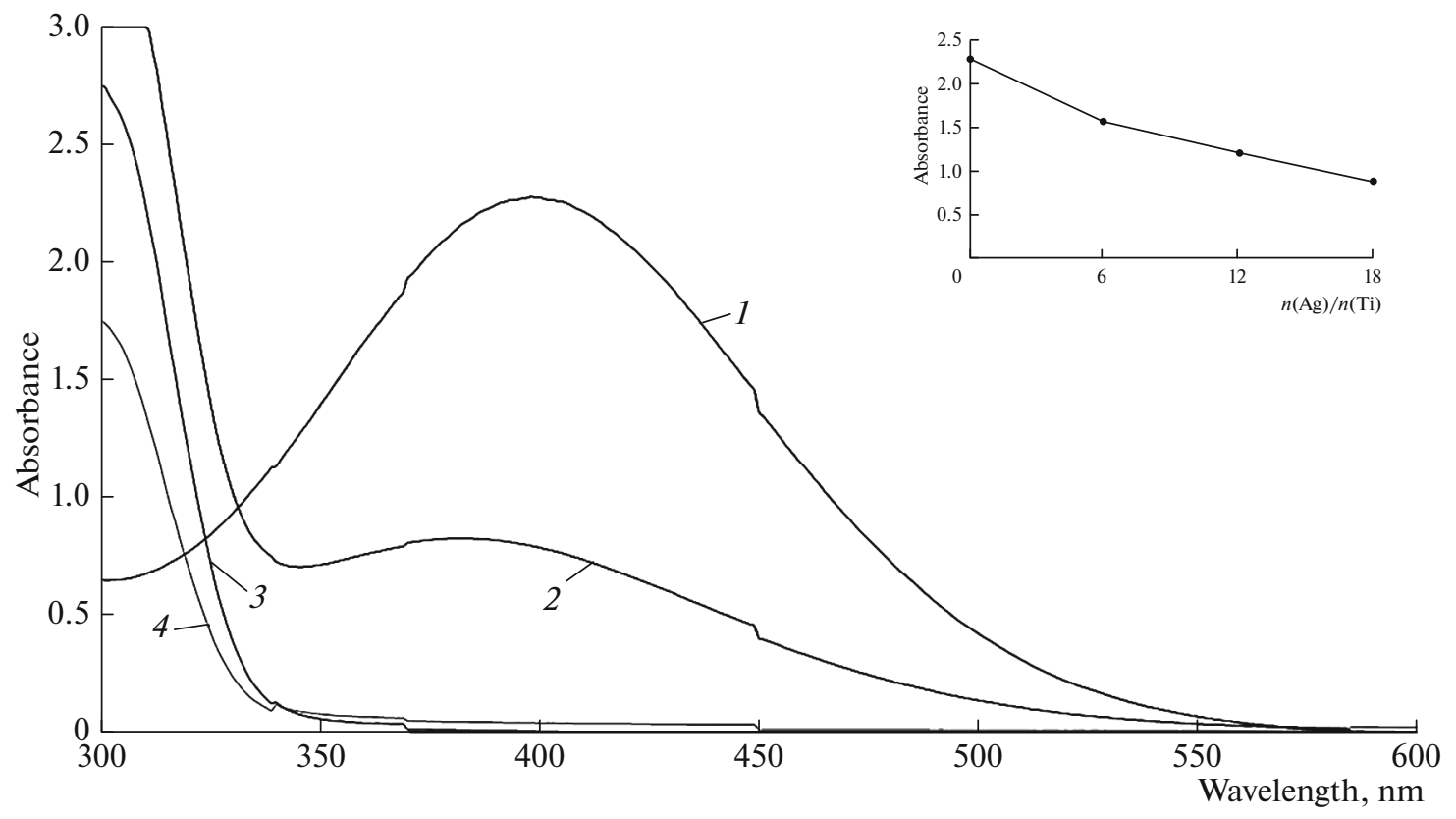

Fig. 2. Electronic absorption spectra of the sols modified by adding different volumes of a $\mathrm{AgNO}_{3}$ solution: (1) no $\mathrm{AgNO}_{3}$, (2) Ag: Ti molar ratio of $6: 1$, (3) $12: 1$, (4) $18: 1$.

Next, we measured the spectra of the sols modified by adding a silver nitrate solution (Fig. 2). It is seen from the spectra in Fig. 2 and the inset therein that the intensity of the absorption band due to the tita-
nium(IV) peroxo complexes (proportional to the concentration of these complexes) decreases monotonically as $\mathrm{Ag}(\mathrm{I})$ cations are added to the sol. Note, however, that the concentration of the peroxo complexes 
(a)

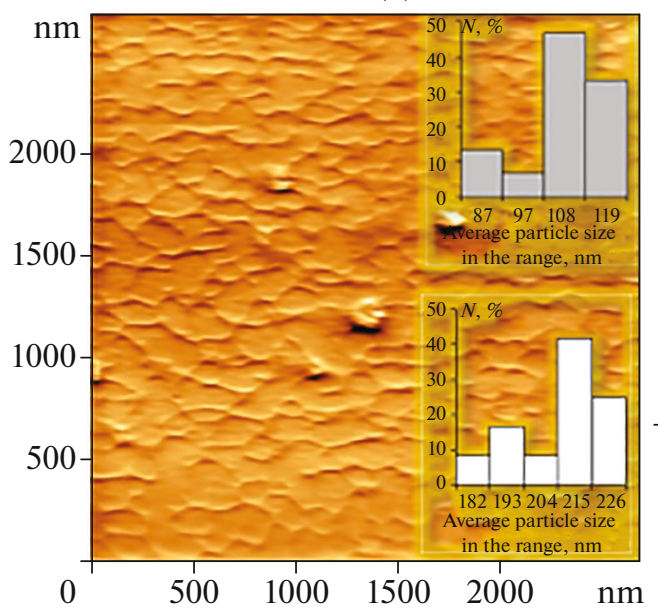

(b)

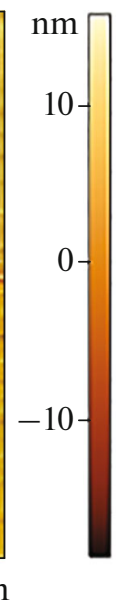

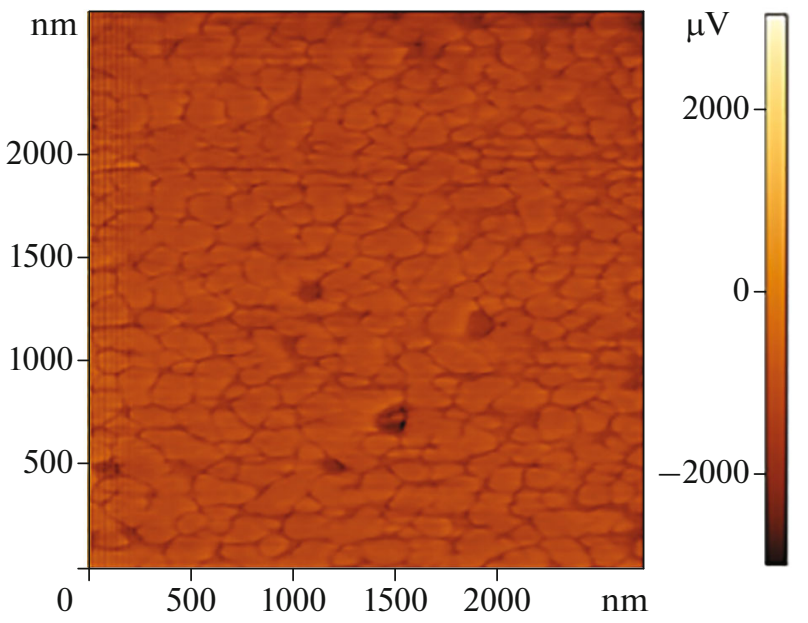

(c)

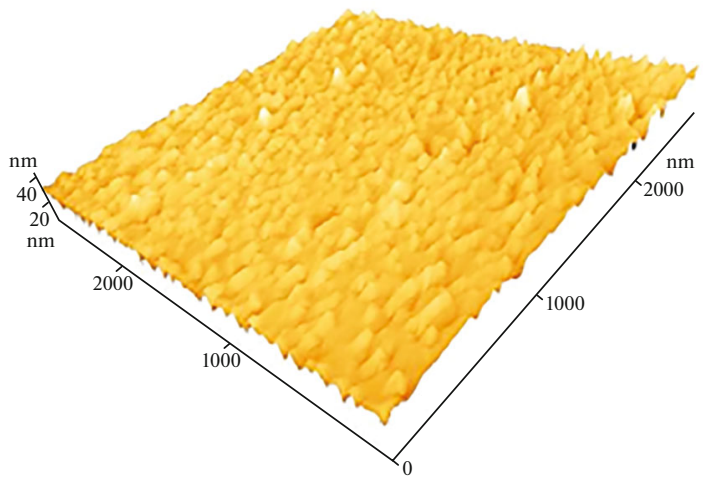

Fig. 3. (a) Height and (b) friction images of the surface of the $\mathrm{TiO}_{2}$ sol containing $\mathrm{Ti}(\mathrm{IV})$ peroxo complexes and (c) $3 \mathrm{D}$ particle height image of the same area.

varies almost linearly with a fivefold excess of the $\mathrm{Ag}^{+}$ concentration added. One possible reason for this is that, because of the large stability constants of the $\mathrm{Ti}(\mathrm{IV})$ peroxo complexes, gradual partial oxidation of the peroxo groups occurs only at a large excess of silver(I) cations, whereas in terms of stoichiometry, the number of silver(I) cations should be just twice that of peroxo groups:

$$
\mathrm{O}_{2}^{2-}+2 \mathrm{Ag}^{+}=\mathrm{O}_{2}+2 \mathrm{Ag}
$$

Scanning probe microscopy. Figure 3 shows images of a characteristic area on the surface of a film produced from the unmodified nano- $\mathrm{TiO}_{2}$ sol stabilized with $\mathrm{Ti}(\mathrm{IV})$ peroxo complexes and the corresponding particle size distributions (Fig. 3a, insets). These data lead us to conclude that the thickness of the film does not exceed $40 \mathrm{~nm}$. The particles are oblong in shape, predominantly monodisperse $(80 \%$ of the particles are 92 to $125 \mathrm{~nm}$ in size "along their short axis" and twice that "along their long axis"), and slightly aggregated.
Figure 4 presents images of a film grown on mica using the product of reaction between the sol described above and $0.1 \mathrm{M} \mathrm{AgNO}_{3}$ (at a Ti : Ag molar ratio of $1: 6$ ). The micrographs show well-defined "islands" $\sim 16 \mathrm{~nm}$ in height (with an average diameter of $240 \mathrm{~nm}$ ). Note that the contours of the "basic" nanoparticles are extremely fuzzy. The observed changes in the micromorphology of the film can be tentatively attributed to the onset of a redox reaction between $\mathrm{Ag}(\mathrm{I})$ and peroxo groups, which leads, on the one hand, to a decrease in the aggregative stability of the nano- $\mathrm{TiO}_{2}$ and, on the other, to the formation of Ag clusters.

Figure 5 shows images of an area of a film grown on mica using the product of reaction between the sol described above and a $0.1 \mathrm{M} \mathrm{AgNO}_{3}$ solution (at a $\mathrm{Ti}: \mathrm{Ag}$ molar ratio of $1: 18$ ). The micrographs demonstrate stronger aggregation of the titanium-containing particles and growth of, probably, silver-containing particles (presumably, Ag nanoparticles). These changes in the micromorphology of the film can be accounted for 
(a)

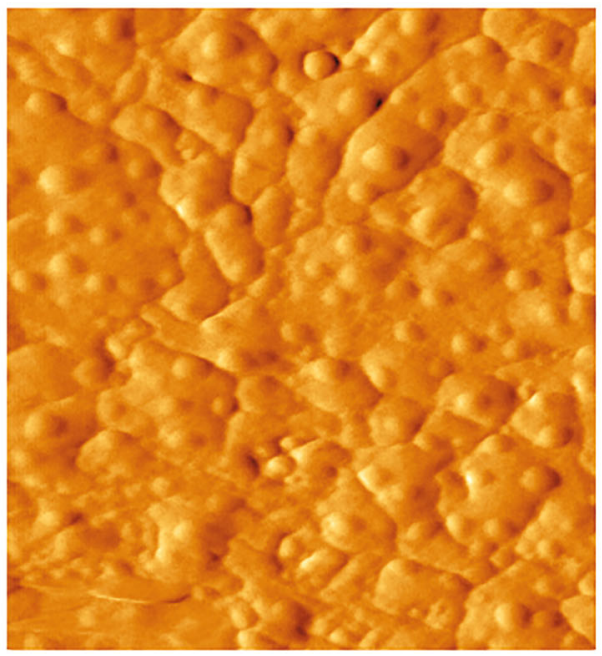

(b)

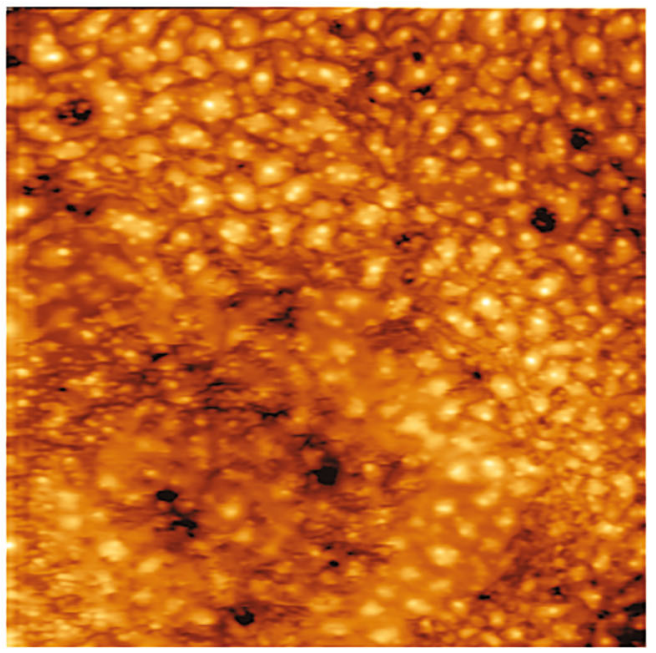

(c)

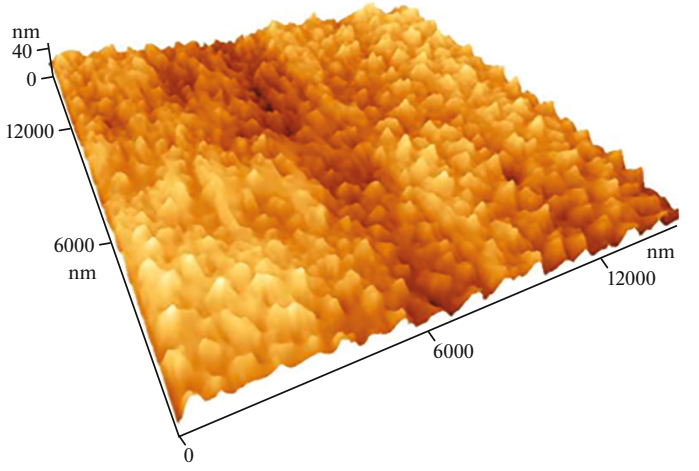

Fig. 4. (a) Height and (b) friction images of the surface of the sol with $\mathrm{Ti}: \mathrm{Ag}=1: 6$ and (c) 3D particle height image of the same area.

by an increase in the extent of the processes described above, involving redox interaction between $\mathrm{Ag}^{+}$and peroxo groups. We plan to verify these assumptions using at least scanning electron microscopy and X-ray microanalysis.

UV-induced bleaching kinetics. The kinetic curves of sol bleaching in Figs. 6a and $6 \mathrm{~b}$ lead us to assume that the process under consideration is a pseudo-first-

Table 1. Rate constant for photodestruction of the sols differing in $\mathrm{Ti}$ : Ag ratio

\begin{tabular}{l|c}
\hline \multicolumn{1}{c|}{ Ti $:$ Ag } & $\begin{array}{c}\text { Photodestruction rate } \\
\text { constant }\end{array}$ \\
\hline No silver nitrate (Fig. 6, curve 1) & 0.007 \\
$1: 6$ (Fig. 6, curve 2) & 0.014 \\
$1: 18$ (Fig. 6, curve 3) & 0.026 \\
\hline
\end{tabular}

order reaction. Table 1 presents the rate constant of this reaction for sols with different Ti : Ag ratios. It is seen that the rate constant is an almost linear function of the amount of silver(I) cations added to the sol, which makes it possible to control the bleaching rate by varying the silver cation concentration.

\section{CONCLUSIONS}

The present results on nano- $\mathrm{TiO}_{2}$ sols containing $\mathrm{Ti}(\mathrm{IV})$ peroxo complexes lead us to assume that it is reasonable to further optimize targeted sol synthesis processes for producing light-time-temperature indicators adapted to particular features of sols. On the other hand, spectroscopic data and SPM images are of interest for gaining insight into correlated processes of the aggregation of some nanoparticles and nucleation of others.

The present dynamic light scattering data demonstrate that the size of the titanium dioxide particles is in the nanometer range throughout the sol samples. 
(a)

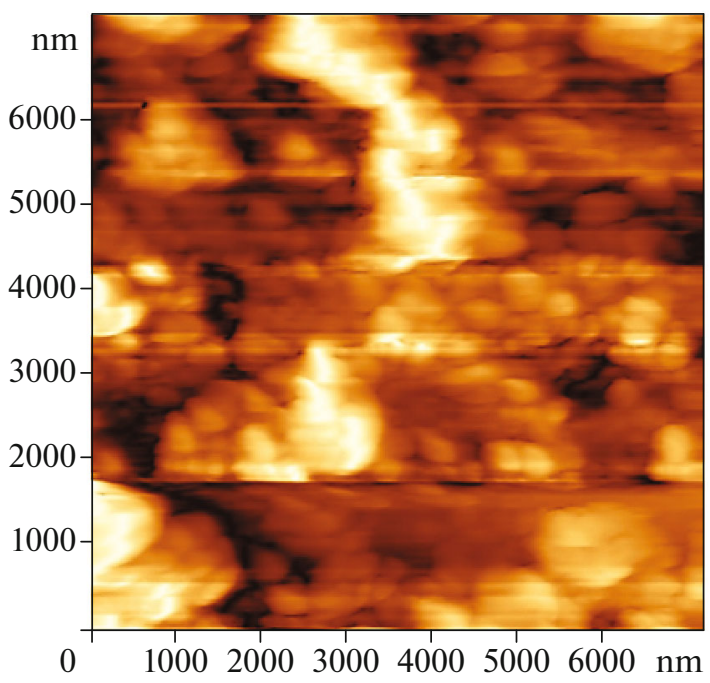

(b)

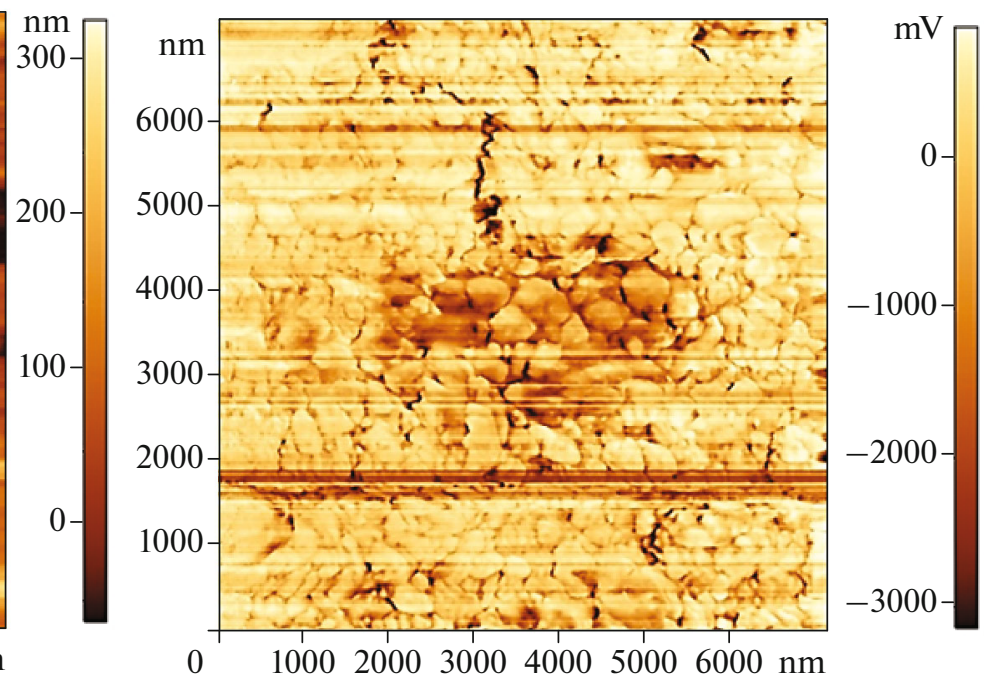

(c)

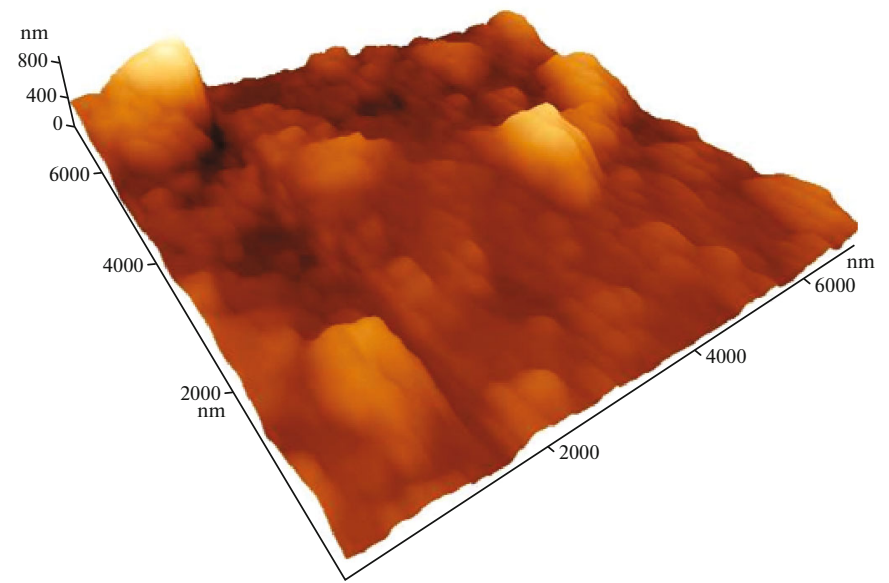

Fig. 5. (a) Height and (b) friction images of the surface of the sol with $\mathrm{Ti}: \mathrm{Ag}=1: 18$ and (c) $3 \mathrm{D}$ particle height image of the same area.
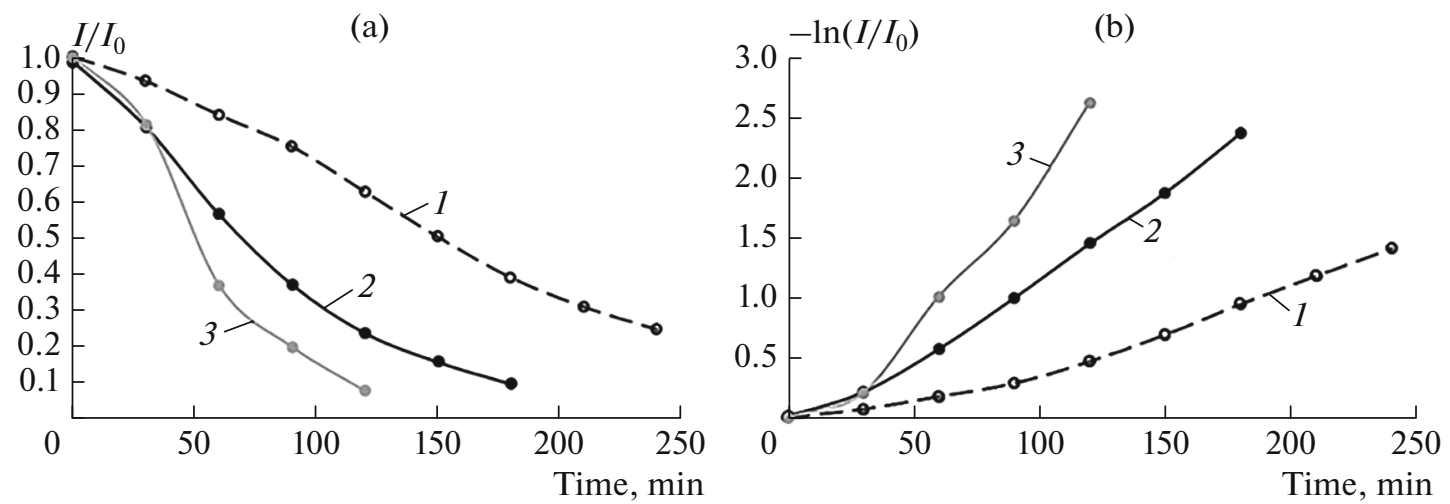

Fig. 6. Kinetic curves for the photodestruction of peroxo groups in the $\mathrm{TiO}_{2}$ and $\mathrm{TiO}_{2} / \mathrm{Ag}$ sols: (a) linear scales, (b) semilog plot; $(1-3)$ see Table 1.

According to the electronic absorption spectroscopy results, the intensity of the absorption band due to the peroxo groups decreases monotonically with increasing sol $\mathrm{pH}$ or on the addition of silver cations. Moreover, the linear dependence of the intensity of this band on fivefold silver cation concentration attests 
indirectly to high stability of the Ti(IV) peroxo complexes.

The SPM results indicate that the surface height difference in the films does not exceed $80 \mathrm{~nm}$ and that the addition of silver cations leads to disordering of the initially uniform films, producing surface silver clusters $\sim 16 \mathrm{~nm}$ in height (with an average diameter of $240 \mathrm{~nm}$ ). In this process, the contours of the "basic" titanium-containing nanoparticles become fuzzy. As the silver cation concentration increases further, these changes become more pronounced.

Experimental kinetic data show that the rate of sol bleaching (due to peroxo group destruction) increases in parallel with increasing $\mathrm{pH}$ or silver cation concentration.

\section{FUNDING}

This work was supported by the Russian Federation Ministry of Science and Higher Education, project no. 0706-2020-0026.

\section{REFERENCES}

1. Zhang, C., Yin, A.X., Jiang, R., et al., Time-temperature indicator for perishable products based on kinetically programmable Ag overgrowth on $\mathrm{Au}$ nanorods, ACS Nano, 2013, vol. 7, no. 5, pp. 4561-4568.

2. Atchareeya, N., Chanassa, N., Waraporn, B., et al., Response modelling of time-temperature indicator based on polydiacetylene/silica nanocomposite, 19th IAPRI World Conf. on Packaging, Melbourne, 2014.

3. Koutsoumanis, K., Taoukis, P.S., and Nychas, G.J.E., Development of a safety monitoring and assurance system for chilled food products, Int. J. Food Microbiol., 2005 , vol. 100 , nos. $1-3$, pp. 253-260.

4. Han, J.H., Ho, C.H.L., and Rodrigue, E.T., Intelligent packaging, in Innovation in Food Packaging, London: Elsevier, 2005, pp. 138-155.

5. Hashimoto, K., Irie, H., and Fujishima, A., $\mathrm{TiO}_{2}$ photocatalysis: a historical overview and future prospects, AAPPS Bull., 2007, vol. 17, no. 6, pp. 12-29.

6. Haider, A.J., Jameel, Z.N., and Al-Hussaini, I.H.M., Review on: titanium dioxide applications, Energy Procedia, 2019, vol. 157, no. 1, pp. 17-29.

7. Savinkina, E.V., Kuz'micheva, G.M., Tabachkova, N.Yu., et al., Synthesis and morphology of anatase and $\eta-\mathrm{TiO}_{2}$ nanoparticles, Inorg. Mater., 2011, vol. 47, no. 5, pp. 521-527.

8. Mellott, N.P., Durucan, C., Pantano, C.G., et al., Commercial and laboratory prepared titanium dioxide thin films for self-cleaning glasses: photocatalytic performance and chemical durability, Thin Solid Films, 2006, vol. 502, pp. 112-120.

9. Shtykov, S.N. and Rusanova, T.Yu., Nanomaterials and nanotechnologies in chemical and biochemical sensors: potentialities and application areas, Ross. Khim. Zh., 2008, vol. 52, no. 2, pp. 92-100.

10. Kreshkov, A.P., Osnovy analiticheskoi khimii. Teoreticheskie osnovy. Kachestvennyi analiz (Principles of Analytical Chemistry: Theoretical Basis and Qualitative Analysis), Moscow: Khimiya, 1970, p. 227.

11. Nag, M., Ghosh, S., Rana, R., et al., Controlling phase, crystallinity, and morphology of titania nanoparticles with peroxo titanium complex: experimental and theoretical insights, J. Phys. Chem. Lett., 2010, vol. 19, no. 1, pp. 2881-2885.

12. Savinkina, E.V., Obolenskaya, L.N., Kuzmicheva, G.M., et al., Introduction of peroxo groups into titania: preparation, characterization and properties of the new peroxo-containing phase, CrystEngComm, 2015, vol. 17, pp. 7113-7123.

13. Kuzmicheva, G.M., Obolenskaya, L.N., and Saviocnkina, E.V., RF Patent 2520100, 2014.

14. Savinkina, E.V., Obolenskaya, L.N., Kuzmicheva, G.M., et al., Effects of peroxo precursors and annealing temperature on properties and photocatalytic activity of nanoscale titania, J. Mater. Res., 2018, vol. 33, no. 10, pp. $1-11$.

15. Yaminsky, I.V., Akhmetova, A.I., Meshkov, G.B., and Olenin, A.V., Scanning probe microscopy of 2D nanostructures for energy storage units and catalysts, Nanoindustriya, 2019, vol. 12, no. 2, pp. 148-151.

16. Kumar, K., Godavarthi, S., Karthik, T.V., et al., Green synthesis of S-doped rod shaped anatase $\mathrm{TiO}_{2}$ microstructures, Mater. Lett., 2016, vol. 183, pp. 211-214.

17. Ubonchonlakate, K., Sikong, L., and Saito, F., Photocatalytic disinfection of $\mathrm{P}$ Ae-Ruginosa bacterial Agdoped $\mathrm{TiO}_{2}$ film, Proc. Eng., 2012, vol. 32, pp. 656662 .

18. Muflikhun, M.A., Chua, A.Y., and Santos, G.N.C., Structures, morphological control, and antibacterial performance of $\mathrm{Ag} / \mathrm{TiO}_{2}$ micro-nanocomposite materials, Adv. Mater. Sci. Eng., 2019, paper 9821535.

19. Tryba, B., Piszcz, M., and Morawski, A.V., Photocatalytic and self-cleaning properties of Ag-doped $\mathrm{TiO}_{2}$, Open Mater. Sci. J., 2010, vol. 4, no. 1, pp. 5-8.

20. Rodriguez, C., Di Cara, A., Renaud, F., Freney, J., Horvais, N., Borel, R., Puzenat, E., and Guillard, C., Antibacterial effects of photocatalytic textiles for footwear application, Catal. Today, 2014, vol. 230, pp. 41-46.

Translated by $O$. Tsarev 